\title{
Optical generation of microwave signals by the use of phase locked semiconductor lasers
}

Gliese, Ulrik Bo; Christensen, Erik Lintz; Nielsen, Torben Nørskov; Stubkjær, Kristian

Published in:

LEOS 1991 Summer Topical Meetings on Spaceborne Photonics: Aerospace Applications of Lasers and Electro-Optics

Publication date:

1991

Document Version

Publisher's PDF, also known as Version of record

Link back to DTU Orbit

Citation (APA):

Gliese, U. B., Christensen, E. L., Nielsen, T. N., \& Stubkjær, K. (1991). Optical generation of microwave signals by the use of phase locked semiconductor lasers. In LEOS 1991 Summer Topical Meetings on Spaceborne Photonics: Aerospace Applications of Lasers and Electro-Optics: Optical Millimeter-Wave Interactions: Measurements, Generation, Transmission and Control (pp. 51-52). IEEE.

\section{General rights}

Copyright and moral rights for the publications made accessible in the public portal are retained by the authors and/or other copyright owners and it is a condition of accessing publications that users recognise and abide by the legal requirements associated with these rights.

- Users may download and print one copy of any publication from the public portal for the purpose of private study or research.

- You may not further distribute the material or use it for any profit-making activity or commercial gain

- You may freely distribute the URL identifying the publication in the public portal 


\title{
FA.2 Optical Generation of Microwave Signals by the Use of Phase Locked Semiconductor Lasers
}

\author{
U. Gliese, E. Lintz Christensen, T.N. Nielsen and K. Stubkjær \\ Center for Broadband Telecommunications \\ Electromagnetics Institute, Technical University of Denmark \\ Building 348, DK-2800 Lyngby, Denmark
}

Future satellite antennas may be implemented as active phased array antennas based on a large number of active microwave array elements. The signal distribution is a difficult task and conventional feeds using waveguides or coaxial cables will not be feasible for antennas with a large number of bearns. By contrast, fibre optic links offer an attractive solution for the distribution of the signals in a phased array antenna system [1].

The basic principle of the coherent optical beam forming network (OBFN) is the generation of the microwave carrier by the beating of two lasers as shown in Fig. 1. Unfortunately, the carrier phase stability requirements in a microwave satellite link are very high [2]. It is therefore, important to know the influence of the laser phase noise. Consequently, the required total laser linewidth were calculated by relating the rms phase error in the microwave receiver to the phase noise of the lasers in the coherent OBFN [3]. Results are listed in Table 1 for two of the bit rates normally used in satellite links. Clearly, these requirements are not easily fulfilled with semiconductor lasers.

When the two lasers are phase locked, as shown in Fig. 1, the phase fluctuations of the difference frequency will be modified with the transfer function of the locking loop [4]. Consequently, the phase noise reduction (PNR) obtained with ideal first and second order phase locked loops (PLLs) has been calculated. The results are shown in Fig. 2 together with the maximum theoretical limit of the PNR.

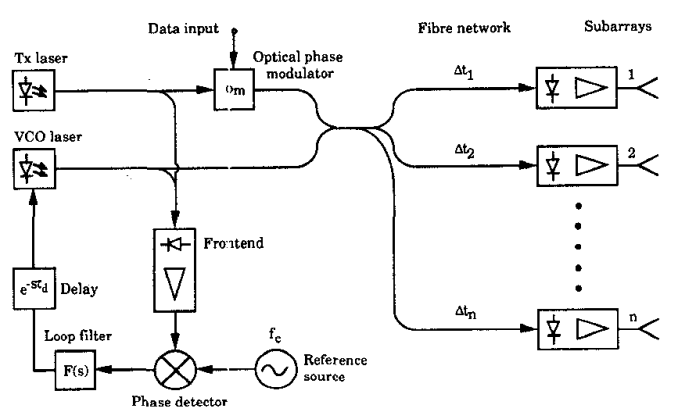

Figure 1: Schematic of a coherent optical beam forming network (OBFN) consisting of an optical phase locked transmitter module, an optical phase modulator, a fibre optic distribution network, and an active phased array antenna with $\mathrm{n}$ subarrays.

\begin{tabular}{|c|c|c|}
\hline $\begin{array}{c}\text { QPSK bit rate } \\
\text { Mbit/s }\end{array}$ & \multicolumn{2}{|c|}{ Required linewidth in $\mathrm{KHz}$} \\
\cline { 2 - 3 } & $\begin{array}{c}1^{\circ} \mathrm{rms} \\
\text { phase error }\end{array}$ & $\begin{array}{c}2^{\circ} \mathrm{rms} \\
\text { phase error }\end{array}$ \\
\hline 33 & 1.2 & 4.8 \\
\hline 131 & 4.8 & 19 \\
\hline
\end{tabular}

Table 1: Total laser linewidth requirements in coherent OBFNs.

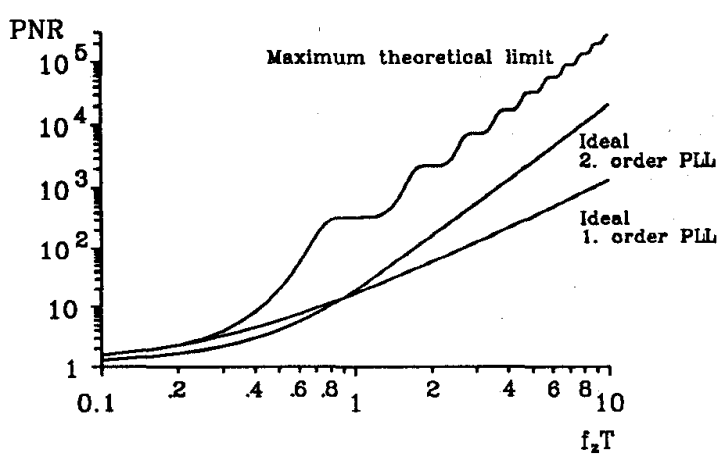

Figure 2: Phase noise reduction as a function of normalized loop bandwidth $f_{z} T$. 
The limit of the PNR is reached when all the phase noise below the normalized loop bandwidth $f_{z} T$ is removed. Here $\mathrm{f}_{\mathrm{z}}$ is the open loop zero $\mathrm{dB}$ frequency and $\mathrm{T}$ is the symbol time which corresponds to the bit rate as $R_{b}=\frac{2}{T}$ (QPSK modulation).

From Fig. 2 it is seen that a large amount of phase noise can be suppressed by the use of broadband PLLs. However, when designing broadband PLLs the loop propagation delay $\tau_{\mathrm{d}}$ may have a large influence on both the PNR and the loop stability. Therefore, the PNR has been calculated taking the loop propagation delay into account. The PNR is shown in Fig. 3 for the second order loop, which seems the most interesting for obtaining high PNRs. In addition, the demand placed on the laser linewidth to ensure stable locked loop operation has been calculated and is shown in Fig. 4. It is obvious that the loop propagation delay has a large influence on the PNR obtained with broadband PLLs. Furthermore, the loop propagation delay drastically limits the area of stable locked loop operation. Therefore, the loop propagation delay cannot be neglected, making careful loop design very important.

The results from Fig. 3 and Fig. 4 shows that it is possible to optically generate highly stable microwave carriers by the use of phase locked semiconductor lasers with linewidths in the order of MHz. Unfortunately, DFB lasers tend to have a dip in the frequency response at low frequencies which will disturb the PLL. Multi-electrode DFB lasers on the other hand seem very promising since both narrow linewidth, uniform frequency response and high modulation sensitivity can be obtained [5].

In conclusion the strict demands placed on linewidth of the lasers in a coherent OBFN seem possible to fulfil with narrow linewidth semiconductor DFB lasers when using PLLs, thereby making the coherent approach realistic for optical generation of high quality microwave signals.

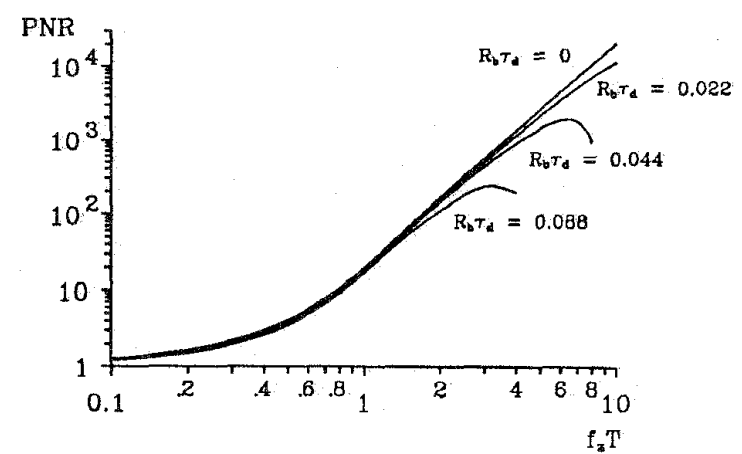

Figure 3: Phase noise reduction obtained with a second order loop as a function of normalized loop bandwidth for different values of normalized loop propagation delay.

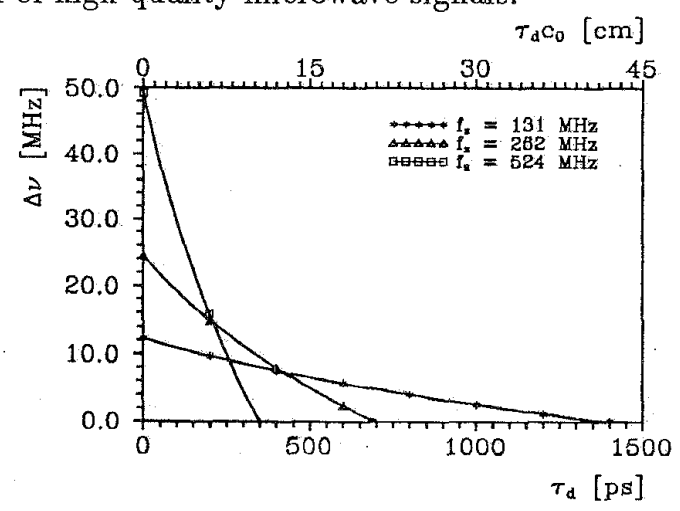

Figure 4: Laser linewidth demand for stable locked loop operation as a function of propagation delay and loop bandwidth for an average time to cycle slip of 10 years.

\section{References}

[1] A. Daryoush et al: Microwave Journal, vol. 30, no. 3, pp. 97-104, 1987.

[2] Intelsat earth station standards (IESS), Document IESS-309 (Rev. 2), 1990, p. 14.

[3] U. Gliese et al: In Proceedings of CLEO, 1991, paper CWM5.

[4] A. Blanchard: Phase-Locked Loops, John Wiley \& Sons, New York 1976.

[5] R. J. S. Pedersen et al: In Proceedings of ECOC, 1990, paper TuF3.3. 